\title{
Choice of Employment as a Category Differentiating Peripheral Employees
}

\author{
Małgorzata Dobrowolska \\ Silesian University, Institute of Psychology, Faculty of Work and Organisational Psychology \\ malgorzata.dobrowoska@us.edu.pl
}

\section{Doi:10.5901/mjss.2015.v6n2s2p127}

\begin{abstract}
Some people deliberately choose alternative employment due to its flexibility, freedom and variety of tasks offered. Individuals preferring this type of employment mainly due to the said characteristics are referred to as voluntary employees. A coercive flexible employee is someone who perceives his/her employment as unattractive and undesirable, and it is only inability and lack of chances to find a permanent or a different type of employment that makes them choose this type of employment for a specified period of time or on short-term basis. Given the choice between a flexible form of employment and "permanent" job, assuming that conditions offered are acceptable, they do not hesitate to choose the latter.
\end{abstract}

Keywords: autonomy of employment, flexible forms of employment, peripheral employees

\section{Introduction}

Attitude to work depends on the personality of an individual Banka divided personalities with respect to attitudes to duties performed (1996). He described two types: professional personality and compelled personality. A professional personality is a personality of individuals for whom work has an important psychological meaning and is an integral part of their personality. Work is a part of one's life, an individual identifies and integrates with it strongly. The second type of personality is people bored with their jobs, who treat their work as a necessary duty, a monotonous part of life allowing to earn one's living. An attitude to work creates a division of a personality. One can speak of a work time producers (like for example workaholics) and work time consumers (individuals alienated from work). This translates very often into an attitude to perception of employment itself - one's own choice or coercion.

The research conducted so far point at significant differences that characterise reasons for choosing a nontraditional form of work. Some people deliberately choose alternative employment due to its flexibility, freedom and variety of tasks offered. Individuals preferring this type of employment mainly due to the said characteristics are referred to as voluntary employees. A coercive flexible employee is someone who perceives his/her employment as unattractive and undesirable, and it is only inability and lack of chances to find permanent or a different type of employment makes them choose this type of employment for a specified period of time or on short-term basis. Given the possibility to choose between the flexible and "permanent" job, assuming that conditions offered are acceptable, they do not hesitate to choose the latter.

\section{Presentation of the Author's Research}

A group of analysed variables, which affect the functioning of an individual in flexible forms of employment are personal characteristics. One of them is autonomy of the choice of employment. This is the willingness or reluctance that guides an employee in his choice of employment, a sense that he is employed with a certain form of employment by his own choice (voluntarily) or compulsorily (due to certain circumstances), in accordance with the research by J. E. Ellington, M. L. Gruys, P. R. Sackett, (1998). In this study it has been diagnosed with the set of 3 questions.

The results of the test for $n=2118$ peripheral employees show that the vast majority of flexible employees treat their form of employment as their conscious choice. $80.1 \%$ of all the respondents claim that are currently employed, because they want to work this way and they would not change their work for anything else. Only one out of every five respondents treats his work as coercion and claims that he was forced by circumstances to choose it and therefore he would be willing to change it. The vast majority of patients (90.4\%) also argues that the present form of employment suits them. Only $9.6 \%$ of the respondents is of the opposite opinion. Analysed flexible employees are also overwhelmingly satisfied with their employment conditions. $89.2 \%$ of the respondents claims that they are generally satisfied with the 
terms and conditions of employment, whereas $10.8 \%$ of the respondents is of the opposite opinion.

Analysis of the answers to the questions (I am currently employed, because this is the way I want to work/because I was forced to by the circumstances; I am satisfied with the form of employment/l am not satisfied with this form of employment; I am/ I am not satisfied with the terms and conditions of my employment) with respect to the forms of employment showed that there is a statistically significant relationship between a form of employment and a sense of autonomy of employment. Dependency analysis was based on ch - square statistics using Kramer's V: for the first question: Kramer's V = 0.132; $p<0.001$.

The highest percentage of individuals declaring their present employment was a conscious choice has been identified in the group of employees working in the social economy (88.1 \%) and among part-time employees (85.3 \%). Whereas the biggest number of individuals for whom work in flexible forms of employment is coercion has occurred in the group of seasonal workers (29.4\%) and among those working for a specified period of time (27.4\%). In case of the latter it may be the case because the work for a specified period of time is the form of employment the most similar to work for an indefinite period of time (permanent job) - a traditional form of employment, and accompanying longing for certainty of employment undoubtedly contributes to the sense of coercion. Seasonal workers are the group that can easily be interpreted by temporariness of employment, due to an undefined period of employment with lack of a possibility to extend a job contract due to characteristics of seasonal employment.

Also the answers to the second question, if the form of employment is satisfactory, are significantly correlated with the form of employment. Kramer's $V=0.143 ; p<0.001$. The value of the ratio indicates that the relationship is weak. The most satisfied with the existing forms of employment are businessmen working part-time, while the least satisfied are seasonal workers. The results are the same as in the case of the first question concerning coercion or choice of employment.

Also in the case of the third question concerning the terms and conditions of employment, when it comes to individuals with flexible forms of employment a statistically significant correlation with the form of employment has been observed. Kramer's $V U=0.165 ; p<0.001$. The value of the ratio indicates that the relationship is weak. In this case also the most satisfied group are the respondents working part-time, and the least satisfied are seasonal workers.

For the record: the variable autonomy of the employment was diagnosed using a set of three questions: $=1 \mathrm{I}$ I am currently employed, a) because I want to work like this and I would not change this work for any other; (b) because circumstances force me to choose it and I would like to change it for some other work; 2. I am satisfied with the form of employment: (a) yes, (b) no; 3. My employment terms and conditions: (a) I am generally satisfied with them; (b) generally I am not satisfied with them. Correlations with social-and-demographic variables are presented in the following paragraphs.

In the case of the first question: I am currently employed, a) because I want to work like this and I would not change this work for any other; (b) because circumstances force me to choose it and I would like to change it for some other work; a significant correlation with the the following variables: education, occupation, sector, industry, has been identified. There is no relation with the other social-and-demographic variables.

Education significantly differentiates responses of the respondents to the analysed question, Kramer's $V=0.136$; $p<0.001$. The higher education, the higher the rate of responders who declare that the work in flexible forms employment was their deliberate choice. In the group of the respondents with education below secondary school the percentage of individuals claiming that this was the case is $64.0 \%$. In the group of the respondents with secondary education the percentage is $79.1 \%$, and in group of people with a university degree $=83.2 \%$.

A correlation of the responses of the respondents with an occupation has been identified: Kramer's $V=0.121$; $p<0.001$. The highest percentage of individual who claim that they want to work under flexible forms of employment and would not change it has been identified among professionals and freelancers (84\%). The same response has been obtained among $80.5 \%$ of individuals in the group of trade and services employees. In the group of managers autonomy is declared by $78.9 \%$ of the respondents, whereas in the group of technicians and civil service officers the rate is $75.6 \%$. The smallest group of individuals who chose their form of employment consciously are workers - $71.6 \%$. The responses to the questions concerning autonomy of the choice is affected by a sector in which individuals operate: Kramer's $\mathrm{V}=$ $0.082 ; p<0.01$. In the group of the respondents working in a social sector $86.6 \%$ made a conscious choice concerning their form of employment. Among those working in the public sector the ratio is $81.8 \%$, and in the group working in the private sector the ratio is $77.2 \%$.

Correlations between the second question concerning satisfaction with the form of employment has been identified with the following variables: sex, education, number of employers, number of children. there has been no other correlation with the other analysed variables.

Sex of the respondents affects the assessment of the form of employment - Kramer's $V=0.095 ; p<0.05$. Men (93 
\%) more often than women (87.4\%) declare that the present form of employment suits them well. Education significantly differentiates responses of the respondents to the analysed question, Kramer's $V=0.139 ; p<0$. 001. People with secondary school education (91.8\%) and a university degree (91.6\%) declare more frequently that their present form of employment suits them well, than people with primary school education $(77.7 \%)$. The response to the test is also affected by the number of former employers: Kramer's $V=0.102 ; p<0.01$. The more employers, the less individuals satisfied with the current form of employment. In the group of the respondents with only one employer so far $93.2 \%$ declares that the current form of employment suits them well. In the remaining groups the result is as follows: $93.1 \%$ in the group of the respondents who already had 2 employers; $90.7 \%$ among the responders who had 3 employers and 86.3 $\%$, among the responders who had 4 or more employers. A correlation between the number of children and satisfaction with a form of employment has been identified as well. Flexible forms of employment are more likely to be preferred by individuals with children ( $94.4 \%$ in the group with 2 or more children and $89.4 \%$ in the group with 1 child) than by childless couples $(87.6 \%)$.

When it comes to the third question, whether the terms and conditions of employment are satisfactory for the respondents, a significant correlations have been identified between this variable and age, education, occupation, sector, number of employers, and duration of contracts.

Assessment of the terms and conditions of employment is correlated with the age of the respondents: Kramer's $V=$ $0.075 ; p<0.05$. Older employees are more satisfied with the terms and conditions of employment than the younger ones: In the age group 41-65 years the percentage of the satisfied is $92.5 \%$; in the age group $31-40$ years $=88.8 \%$, and in the age group 18-65 years $=86.4 \%$. Education significantly differentiates responses of the respondents to the analysed question, Kramer's $V=0.115 ; p<0$. 001 . In the group of the respondents with education below secondary school the percentage of individuals claiming that this was the case is $78.0 \%$. In the group of the respondents with secondary education the percentage is $90.0 \%$, and in group of people with a university degree $=90.4 \%$. A correlation of the responses of the respondents with an occupation has been identified: Kramer's $V=0.119 ; p<0.001$. The more prestigious occupation, the more positive evaluations of flexible employment. The responses to the questions concerning autonomy of the choice is affected by a sector in which individuals operate: Kramer's $V=0.126 ; p<0.001$. In the group of the responders working in the public sector, $93.7 \%$ said that the terms and conditions are generally satisfactory for them. Among those working in the social sector the ratio is $92.1 \%$. In the group of individuals working in the private sector the ratio was $85.5 \%$. Assessment of the conditions of employment depends also on the number of employers so far: Kramer's $V=0.100 ; p<0.001$. The lowest percentage of the respondents who are satisfied with employment terms and conditions occurred in the group of individuals who had already worked in at least 4 places (84.6 \%). In the remaining groups these ratios are 91 - $92 \%$. Duration of employment contracts affects the assessment as well, Kramer's V = 0.109; $p<0.001$. The longer one works for a current employer, the more satisfied with the terms and conditions one is.

\section{Conclusion}

Summing up, more educated employees declare that their choice of a form of their employment was their informed decision, individuals with lower education are experiencing coercion with respect to execution of flexible works. Similarly, when it comes to their posts, the further down the organisational hierarchy, the more coercion and lack of other options is experienced. The most conscious and informed choice of this form of employment was declared by individuals working in the social sector.

When it comes to individuals who are the most satisfied with this form of employment, they are mainly males, persons with primary and secondary education, relatively small number of former employers and bigger number of children (more than two).

The terms and conditions of a flexible form of employment are more satisfactory for older employees, individuals with university degree, employed in the public sector, with a relatively big number of former employers, with longer validity periods of employment contracts.

The research carried out has had a exploratory character. It regarded a new domain of knowledge concerning functioning of an individual in new working conditions, where a characteristic feature is temporariness affecting all aspects of the work, namely "temporary" occupation, "temporary" professional relations, "temporary" parties of a work contract, status of a "temporary" worker, etc. This changes completely the perspective of looking at one's professional future and his further existence, quite different from a permanent employment. A temporary form of employment is becoming increasingly popular in present times. This is due to significant changes in requirements of the labour market and changes in the character of work itself. However, in my opinion, it shall never replace and eliminate the longing for a permanent job. Temporary work is its complement, a different, not necessarily worse form of employment and making 
ones living for selected groups of employees. It is related to a new style of work and the functioning on the market. While remaining one of the tools in the fight with unemployment, it is still only an alternative for a permanent job.

\section{References}

Banka, A. (1996). Psychopatologia pracy. Poznan: Wydawnictwo Gemini.

Ellingson, J. E., Gruys, M. L., Sackett, P. R. (1998). Factors related to the satisfaction and performance of temporary employees. Journal of Applied Psychology, 83, 913-921.

Fieldman, D., Doerpinghaus, H., Turnley, W. (1994). Managing Temporary Workers: A permanent HRR Challenge. Organizational Dynamics, 23, 913-921. 